\title{
Clinical characteristics and outcomes of patients admitted with acute heart failure: insights from a single-center heart failure registry in South India
}

\author{
Aashiq Ahamed Shukkoor ${ }^{1}$, Nimmy Elizabeth George', Shanmugasundaram Radhakrishnan ${ }^{1 *}$, \\ Sivakumar Velusamy², Rajendiran Gopalan', Tamilarasu Kaliappan', Premkrishna Anandan', \\ Ramasamy Palanimuthu' ${ }^{1}$ Vidhyakar Balasubramaniam ${ }^{1}$, Vinoth Doraiswamy ${ }^{1}$ and Arun Kaushik Ponnusamy ${ }^{1}$
}

\begin{abstract}
Background: The epidemiology of HF in India is largely unexplored. Current resources are based on a few hospitalbased and a community-based registry from North India. Thus, we present the data from a single hospital-based registry in South India. Patients admitted with acute heart failure over a period of 1 year were enrolled in the registry and were characterized based on their ejection fraction (EF) measured by echocardiogram. The clinical profile of the patients was assessed, including their in-hospital outcomes. One-way ANOVA and univariate analysis were performed for comparison between three EF-based groups and for the assessment of in-hospital outcomes.

Results: A total of 449 patients were enrolled in the registry, of which 296, 90, and 63 patients were categorized as, HFrEF, HFmrEF, and HFpEF, respectively. The prevalence of HFrEF was higher (65.99\%). The mean age (SD) of the study cohort was $59.9 \pm 13.3$. The majority of the patients presented with acute denovo HF (67\%) and were more likely to be males (65.9\%). The majority of patients presented with warm and wet clinical phenotype (86.4\%). In hospital mortality was higher in HFmrEF (3.3\%).

Conclusion: Patients with HFrEF had high adherence to guideline-directed medical therapy (GDMT). HFrEF patients were also likely to have longer hospital stay along with a worsening of renal function. The in-hospital mortality was comparable between the EF-based groups. Additionally, the association of clinical phenotypes with outcome highlighted that patients in warm and wet phenotype had a longer length of hospital stay, whereas the mortality and worsening renal function rates were found to be significantly higher in the cold and wet group.
\end{abstract}

Keywords: Heart failure, Registry, Mortalities, In-hospital

Background Heart failure is a clinical syndrome which is progressive in nature. A rise in cardiovascular risk factors has led to a perpetual escalation in the prevalence and incidence of HF [1]. Additionally, the presence of myriads of comorbid conditions associated with HF

\footnotetext{
* Correspondence: aashiq_ahamed@ymail.com

'Department of Cardiology, PSG Institute of Medical Sciences and Research, Coimbatore, Tamilnadu, India

Full list of author information is available at the end of the article
}

imposes a major economic burden [2]. Despite significant developments in the management of chronic HF, it still remains a public health issue with worse prognosis leading to several million hospitalizations worldwide [3, $4]$. According to the INDUS study, the estimated prevalence of HF in India in 2016 was 1\% of the total population; that is about 8 to 10 million patients. The HF burden in India based on the existing evidence is alarming [5].

\section{Springer Open}

(c) The Author(s). 2021 Open Access This article is licensed under a Creative Commons Attribution 4.0 International License, which permits use, sharing, adaptation, distribution and reproduction in any medium or format, as long as you give appropriate credit to the original author(s) and the source, provide a link to the Creative Commons licence, and indicate if changes were made. The images or other third party material in this article are included in the article's Creative Commons licence, unless indicated otherwise in a credit line to the material. If material is not included in the article's Creative Commons licence and your intended use is not permitted by statutory regulation or exceeds the permitted use, you will need to obtain permission directly from the copyright holder. To view a copy of this licence, visit http://creativecommons.org/licenses/by/4.0/. 
At present, the understanding of HF burden and management is based on western guidelines, with poor representation of low-resource countries. Contemporary HF data from developing and low-middle income countries are sparse, and the epidemiology of HF in India is largely unexplored. Current resources are based on a few hospital-based registries and a community-based registry [5-9]. We present the data from a single hospital-based registry in South India in order to compare the causes of hospitalization, clinical presentation, management strategies, and outcome with other national and international registries. The data could be used for identification of key factors of HF hospitalization in India and development of native guidelines in low-resource countries.

The prime objectives of this registry were (i) to describe the precipitating factors for hospitalization and the clinical characteristics of HF patients, (ii) to describe the diagnosis and pharmacological strategies of management in HF patients, and (iii) to describe the in-hospital outcome of patients admitted with HF.

\section{Methods}

We initiated a prospective, single-center hospital-based registry of patients admitted with heart failure from July 2018 to July 2019 at PSG hospitals, Coimbatore. The study was approved by the institutional human ethics committee (19/275), Coimbatore, India. This registry was established as a part of the quality improvement program and to monitor the in-hospital outcomes of HF patients.

Data was collected systematically by clinical pharmacist, a member of the multidisciplinary HF team. A total of 449 patients were enrolled. Precipitating factors for decompensation were documentedby means of a structured interview of patients or their caretakers. Patients were diagnosed with HF based on signs, symptoms, echocardiography, and natriuretic peptide levels if available. Eligible patients were categorized based on left ventricular ejection fraction (LVEF) into heart failure with reduced ejection fraction (LVEF $<40 \%$ ), mid-range ejection fraction (LVEF 41-49\%), and preserved ejection fraction $(\geq 50 \%)$, measured using the Simpson method. The study cohort was also classified based on clinical phenotype, according to Forrester's classification to determine the in-hospital outcome in each of the phenotype.

The clinical outcomes of patients during their course in hospital such as the length of stay, in-hospital mortality, NYHA class at discharge and worsening renal function were assessed. Worsening renal function was defined as a rise in serum creatinine levels by more than $30 \%$ from baseline. The aforementioned clinical outcome parameters were analyzed across the entire spectrum of
LVEF. Clinical outcome parameters were categorized based on clinical phenotype of patients as well.

\section{Inclusion and exclusion criteria}

All patients admitted with HF irrespective of etiology and age more than 18 years were enrolled in the registry.

\section{Data collection}

Patient's demographic details, medical history, comorbidities, risk factors, and presenting signs and symptoms were included in the data collection. Diagnostic information like laboratory parameters and details of invasive and non-invasive diagnostic procedures were recorded. The prevalence of anemia across the subcategories was analyzed in this study wherein anemia was defined as hemoglobin $<12 \mathrm{~g} / \mathrm{dl}$ in females and $<13 \mathrm{~g} / \mathrm{dl}$ in males, as defined by the World Health Organization. The serum iron level was evaluated for all patients with anemia and also for all affordable patients without anemia. Iron deficiency was defined as ferritin $<100 \mu \mathrm{g} / \mathrm{l}$ or ferritin of $100-299 \mu \mathrm{g} / \mathrm{l}$ with a transferrin saturation< $20 \%$.

Echocardiographic details like left ventricular systolic and diastolic function, details of valvular abnormalities, the presence of pulmonary hypertension, and right ventricular function were registered.

Pharmacological management of patients, such as inclusion of neurohormonal blockers and other supportive medications was included. The precipitating factors for acute decompensation were captured. Invasive procedures during the hospital admission like percutaneous coronary intervention (PCI), coronary artery bypass grafting (CABG), intra-aortic balloon pump (IABP), implantable cardio-defibrillator (ICD), cardiac resynchronization therapy (CRT), and pacemaker implantation (PPI) were recorded.

\section{Statistical analysis}

Continuous variables were presented as median and categorical variables were presented as percentages. Univariate analysis was performed to identify the associationof three EF groups within hospital mortality. In univariate analysis, the hazard ratio (HR) with $95 \%$ confidence intervals $(\mathrm{CI})$ was calculated, respectively. Statistical significance was defined as $p$ values $<0.05$. SPSS 24.0 (IBM Corporation, New York, USA) was used for all statistical analyses.

\section{Results}

A total of 449 patients admitted with HF under the Department of Cardiology during the study period (July 2018 to July 2019) were enrolled in the registry. Patients were stratified based on their EF determined by 
echocardiography. HFrEF constituted $65.9 \%$ of patients, while HFmrEF and HFpEF made up to $20 \%$ and $14.03 \%$ of the patients admitted with heart failure, respectively. About $67 \%$ of patients presented with acute de novo heart failure, while $32.9 \%$ of patients presented with acute decompensated heart failure.

The mean age (SD) of the study population was $59.9 \pm$ 13.3 years. The mean age of patients in all the three EFbased groups were similar with no statistically significant difference. Among the total enrollees, 296 (65.9\%) were males and 153 (34.9\%) were females. Both HFrEF and HFmrEF groups showed a male predominance $(71.62 \%$ vs.61.1\%) whereas HFpEF group had a marginally higher number of female patients $(53.9 \%)(p<0.05)$.

Type 2 diabetes mellitus was the most prevalent comorbidity in HFrEF and HFmrEF groups $(62.8 \%$ and $56.6 \%)(p<0.001)$, whereas systemic hypertension was the most prevalent comorbidity in the HFpEF group. Coronary artery disease (CAD), chronic obstructive pulmonary disease (COPD), and chronic kidney disease (CKD) were the other relevant comorbiditiesin the study population, as elaborated in Table 1.

Mean admission systolic blood pressure was $119.3 \pm 25$ $\mathrm{mmHg}$ in patients with HFrEF, $126 \pm 24.3 \mathrm{mmHg}$, and 124.8 $\pm 25.4 \mathrm{mmHg}$ in patients with HFmrEF and HFpEF, respectively. While breathlessness was the most common presenting symptom in HFrEF and HFpEF group, tiredness and weight gain were the most presenting symptoms in HFmrEF group.

The prevalence of left bundle branch block was the highest in the HFrEF group (10.4\%). Patients with HFpEF were found to have a higher incidence of right ventricular dysfunction (9.5\%) in comparison to HFmrEF and HFpEF groups. Mitral regurgitation and tricuspid regurgitation were more often detected in patients with HFrEF (70.6\%, 28.7\%). The mean left ventricular ejection fraction of patients with HFrEF was $32.02 \pm 5.9,43.3 \pm 2.9$ in HFmrEF and $57.7 \pm 5.3$ in HFpEF. The mean right ventricular systolic pressure (RVSP) of the study population was $50.8 \pm 15.1$. There was no statistical difference in the RVSP of patients in the three EF-based subgroups $(p>0.05)$.

The prevalence of anemia in our cohort was $41.6 \%$. More than half of the patients in HFmrEF and HFpEF groups were found to have anemia (55.5\% and 52.3\%), while anemia prevailed in $35.13 \%$ of patients in the HFrEF group. Among HF patients with anemia, iron deficiency was prevalent in $93.6 \%$. Of patients without definite anemia, serum iron levels could be estimated only in $24.9 \%$ due to reasons of unaffordability wherein $30.63 \%$ of patients were found to have low serum iron level. Iron was substituted in intravenous form as ferric carboxymaltose in all patients with iron deficiency.
A significantly higher proportion of patients with HFrEF had presented with a baseline renal dysfunction due to CKD or AKI, when compared to other subgroups. Natriuretic peptide (NT-proBNP) levels were available only in $17.8 \%$ of the total patients. In patients with $\mathrm{HFrEF}$, the mean $\pm \mathrm{SD}$ values were $7467.7 \pm 8381$. In HFmrEF and HFpEF groups, the mean \pm SD values were $13662 \pm 14310$ and $3788 \pm 4810.6$, respectively.

Hypokalemia was the most common electrolyte abnormality across all the EF-based subgroups; the majority being in HFrEF group (23.6\%) followed by $11.1 \%$ and $19 \%$ in HFmrEF and HFpEF groups, respectively. About 34 patients were noted to have hyperkalemia in the study cohort, among which, HFmrEF group had higher number of patients with raised potassium levels (10\%). Sodium levels were available in 132 patients, of which 10 patients $(7.57 \%)$ were observed to have hyponatremia.

The study cohort was classified based on clinical phenotype, according to Forrester's classification. A large share of the patients in the study population presented with congestion without hypoperfusion (warm and wet phenotype) (86.4\%). This finding was consistent with HFrEF group wherein majority of patients were admitted with warm and wet $(87.5 \%)$ followed by $9.1 \%$ of patients with cold and wet and $3 \%$ of patients in warm and dry phenotype. The HFmrEF group also had the highest number of patients in warm and wet category (95.5\%), followed by $3.3 \%$ of patients in warm and dry type. The HFpEF group was unique in terms of clinical phenotype; with the majority of patients being presented with warm and dry phenotype (31.7\%) followed by the warm and wet phenotype $(6.8 \%)$.

The usage of guideline directed medical therapy (GDMT) was analyzed in the HFrEF group. Angiotensinconverting enzyme inhibitors (ACEI)/angiotensin receptor blockers (ARB)/angiotensin receptor neprilysin inhibitors (ARNI) was prescribed in $67.9 \%$ of patients, beta blockers in $57.4 \%$ of patients, and mineralocorticoid receptor antagonist (MRA) was used in $80 \%$ of the HFrEF patients enrolled in the registry (Fig. 1).

Three out of four patients received intravenous diuretics and 1 in 10 patients received inotropes. It was observed that noradrenaline was the most commonly used inotrope in the study population (21 patients) of which, 18 patients were admitted with $\mathrm{HFrEF}$, and 3 patients were admitted with HFmrEF. Intravenous diuretics were used in $86.4 \%$ of patients in HFrEF group, $64.4 \%$ in HFmrEF, and $52.3 \%$ in HFpEF group. All the patients in the study population were prescribed oral diuretics at discharge.

The common interventions underwent by the study population were PCI (2\%), followed by CABG (1.7\%). ICD implantation was done in 2 patients, and CRT was done in 1 patient in the HFrEF group. 
Table 1 Baseline characteristics of patients admitted with heart failure

\begin{tabular}{|c|c|c|c|c|c|}
\hline Variables & $\begin{array}{l}\text { Total } \\
n=449\end{array}$ & $\begin{array}{l}\text { HFrEF } \\
n=296(65.9 \%)\end{array}$ & $\begin{array}{l}\text { HFmrEF } \\
n=90(20 \%)\end{array}$ & $\begin{array}{l}\text { HFpEF } \\
n=63(14.03 \%)\end{array}$ & $p$ value \\
\hline Age & $59.9 \pm 13.3$ & $59.1 \pm 13.6$ & $61.2 \pm 11.7$ & $61.3 \pm 13.5$ & 0.212 \\
\hline \multicolumn{6}{|l|}{ Sex } \\
\hline Male & $296(65.9)$ & $212(71.62)$ & $55(61.1)$ & $29(46.0)$ & 0.000 \\
\hline Female & $153(34.0)$ & $84(28.3)$ & $35(38.8)$ & $34(53.9)$ & 0.000 \\
\hline \multicolumn{6}{|l|}{ Co morbidities } \\
\hline Diabetes & $259(57.6)$ & $186(62.8)$ & $51(56.6)$ & $22(34.9)$ & 0.000 \\
\hline Hypertension & $233(51.8)$ & $158(53.3)$ & $45(50)$ & $30(47.6)$ & 0.694 \\
\hline Obesity & $32(28.5)$ & $24(8.1)$ & $4(4.4)$ & $4(6.3)$ & 0.482 \\
\hline CKD & $60(13.3)$ & $44(14.8)$ & $12(13.3)$ & $4(6.3)$ & 0.212 \\
\hline COPD & $35(7.7)$ & $26(8.7)$ & $5(5.5)$ & $4(6.3)$ & 0.547 \\
\hline CAD & $236(52.5)$ & $180(60.8)$ & $46(51.1)$ & $10(15.8)$ & 0.000 \\
\hline Hepatic dysfunction & $50(11.1)$ & $43(14.5)$ & $6(6.66)$ & $1(1.5)$ & 0.004 \\
\hline \multicolumn{6}{|l|}{ Past medical history } \\
\hline $\mathrm{PCl}$ & $37(8.2)$ & $30(10.1)$ & $6(6.6)$ & $1(1.5)$ & 0.068 \\
\hline CABG & $26(5.7)$ & $21(7.0)$ & $4(4.4)$ & $1(1.5)$ & 0.197 \\
\hline Valve procedures & $19(4.2)$ & $4(1.3)$ & $4(4.4)$ & $11(17.4)$ & 0.000 \\
\hline CRT/ICD & $9(2)$ & $7(2.3)$ & $1(1.1)$ & $1(1.5)$ & 0.736 \\
\hline H/o hospitalization for HF & $79(17.5)$ & $59(19.9)$ & $11(12.2)$ & $9(14.2)$ & 0.264 \\
\hline \multicolumn{6}{|l|}{ Presentation } \\
\hline Acute denovo HF & $301(67)$ & $170(57.4)$ & $72(80)$ & $59(93.6)$ & 0.000 \\
\hline Acute decompensated HF & $148(32.9)$ & $126(42.5)$ & $18(20)$ & $4(6.3)$ & 0.000 \\
\hline \multicolumn{6}{|l|}{ Presentation } \\
\hline Acute denovo HF & $301(67)$ & $170(57.4)$ & $72(80)$ & $59(93.6)$ & 0.000 \\
\hline Acute decompensated HF & $148(32.9)$ & $126(42.5)$ & $18(20)$ & $4(6.3)$ & 0.000 \\
\hline \multicolumn{6}{|l|}{ Presenting symptoms } \\
\hline Pulmonary congestion & $416(92.6)$ & $283(95.6)$ & $81(90)$ & $52(82.5)$ & 0.000 \\
\hline Angina & $48(10.6)$ & $34(11.4)$ & $8(8.8)$ & $6(9.5)$ & 0.745 \\
\hline Syncope/presyncope & $4(0.8)$ & $2(0.6)$ & 0 & $2(3.1)$ & 0.096 \\
\hline Palpitation & $73(16.2)$ & $48(16.2)$ & $13(14.4)$ & $12(19.0)$ & 0.751 \\
\hline Pedal edema & $362(80.6)$ & $253(85.4)$ & $68(75.5)$ & $41(65.0)$ & 0.001 \\
\hline Weight gain & $290(64.5)$ & $241(81.4)$ & $30(33.3)$ & $19(3.0)$ & 0.005 \\
\hline \multicolumn{6}{|l|}{ Vitals } \\
\hline Heart rate $^{\#}(\mathrm{bpm})$ & $94.7 \pm 22.8$ & $95.9 \pm 22.1$ & $96 \pm 23.8$ & $88.2 \pm 24.3$ & 0.041 \\
\hline $\mathrm{SBP}^{\#}(\mathrm{mmHg})$ & $121.17 \pm 25.1$ & $119.3 \pm 25.2$ & $126 \pm 24.3$ & $124.8 \pm 25.4$ & 0.079 \\
\hline Increased JVP & $334(74.3)$ & $241(81.4)$ & $57(63.3)$ & $36(57.1)$ & 0.000 \\
\hline \multicolumn{6}{|l|}{ Electrocardiogram (ECG) } \\
\hline Left bundle branch block & $43(9.5)$ & $31(10.4)$ & $8(8.8)$ & $4(6.3)$ & 0.579 \\
\hline Sinus rhythm & $362(80.6)$ & $255(86.1)$ & $65(72.2)$ & $42(66.6)$ & 0.000 \\
\hline \multicolumn{6}{|l|}{$\mathrm{ECHO}$} \\
\hline Ejection Fraction & $37.8 \pm 10.6$ & $32.02 \pm 5.9$ & $43.3 \pm 2.9$ & $57.7 \pm 5.3$ & 0.000 \\
\hline Grade I diastolic dysfunction & $44(9.7)$ & $19(6.4)$ & $12(13.3)$ & $13(20.6)$ & 0.000 \\
\hline Grade II diastolic dysfunction & $71(1.5)$ & $49(16.5)$ & $11(12.2)$ & $11(17.4)$ & 0.000 \\
\hline Grade III diastolic dysfunction & $149(33.1)$ & $116(39.1)$ & $23(25.5)$ & $10(15.8)$ & 0.000 \\
\hline Left ventricular hypertrophy & $11(2.4)$ & $8(2.7)$ & $1(1.1)$ & $2(3.1)$ & 0.642 \\
\hline Right ventricular dysfunction & $15(3.3)$ & $6(2.0)$ & $3(3.3)$ & $6(9.5)$ & 0.011 \\
\hline Mitral regurgitation & $289(64.3)$ & $209(70.6)$ & $50(55.5)$ & $30(47.6)$ & 0.000 \\
\hline Tricuspid regurgitation & $115(25.6)$ & $85(28.7)$ & $23(25.5)$ & $7(11.1)$ & 0.013 \\
\hline
\end{tabular}


Table 1 Baseline characteristics of patients admitted with heart failure (Continued)

\begin{tabular}{|c|c|c|c|c|c|}
\hline Variables & $\begin{array}{l}\text { Total } \\
n=449\end{array}$ & $\begin{array}{l}\text { HFrEF } \\
n=296 \text { (65.9\%) }\end{array}$ & $\begin{array}{l}\text { HFmrEF } \\
n=90(20 \%)\end{array}$ & $\begin{array}{l}\text { HFpEF } \\
n=63(14.03 \%)\end{array}$ & $p$ value \\
\hline RVSP & $50.8 \pm 15.1$ & $50.1 \pm 12.8$ & $51.2 \pm 15.3$ & $53.7 \pm 23.1$ & 0.464 \\
\hline Pericardial effusion & $93(20.7)$ & $67(22.6)$ & $20(22.2)$ & $6(9.5)$ & 0.000 \\
\hline \multicolumn{6}{|l|}{ Laboratory values } \\
\hline Haemoglobin" ${ }^{\#}(\mathrm{~g} / \mathrm{dL})$ & $12.03 \pm 2.2$ & $12.2 \pm 2.0$ & $11.5 \pm 2.5$ & $11.5 \pm 2.4$ & 0.015 \\
\hline - Male $(<13 \mathrm{~g} / \mathrm{dl})$ & $144(32)$ & $100(33.7)$ & $27(30)$ & $17(27)$ & 0.518 \\
\hline - Female $(<12 \mathrm{~g} / \mathrm{dl})$ & $43(9.5)$ & $4(1.3)$ & $23(25.5)$ & $16(25.3)$ & 0.000 \\
\hline \multicolumn{6}{|l|}{ eGFR $\left(\mathrm{ml} / \mathrm{min} / 1.73 \mathrm{~m}^{2}\right)$} \\
\hline - Admission & $61.9 \pm 32$ & $59.8 \pm 30.8$ & $60.5 \pm 30.9$ & $73.6 \pm 36.4$ & 0.008 \\
\hline - Peak & $55.5 \pm 29.4$ & $53.5 \pm 28.2$ & $53.5 \pm 28.8$ & $67.2 \pm 33.3$ & 0.003 \\
\hline - Discharge & $62 . \pm 34.8$ & $60.6 \pm 35.2$ & $60 \pm 32.6$ & $71.2 \pm 34.9$ & 0.080 \\
\hline \multicolumn{6}{|l|}{ Renal dysfunction } \\
\hline - Male $(\mathrm{Cr}>1.4 \mathrm{mg} / \mathrm{dl})$ & $89(19.8)$ & $68(22.9)$ & $15(16.6)$ & $6(9.5)$ & 0.036 \\
\hline - Female $(\mathrm{Cr}>1.2 \mathrm{mg} / \mathrm{dl})$ & $46(10.2)$ & $28(9.4)$ & $12(13.3)$ & $6(9.5)$ & 0.559 \\
\hline NT-proBNP & $8020 \pm 9835$ & $7467.7 \pm 8381[45]$ & $13662 \pm 14310[10]$ & $3788 \pm 4810.6[11]$ & 0.004 \\
\hline Hyponatremia & $10(2.2)$ & $8(2.7)$ & $2(2.22)$ & 0 & 0.420 \\
\hline Hypokalemia & $92(20.4)$ & $70(23.6)$ & $10(11.1)$ & $12(19.0)$ & 0.034 \\
\hline Hyperkalemia & $34(7.5)$ & $21(7.0)$ & $9(10)$ & $4(6.3)$ & 0.416 \\
\hline \multicolumn{6}{|l|}{ Etiology } \\
\hline $\mathrm{HD}$ & $215(47.8)$ & $173(58.4)$ & $29(32.2)$ & $13(20.6)$ & 0.951 \\
\hline Non ischemic & $171(38)$ & $135(45.6)$ & $15(16.6)$ & $21(33.3)$ & 0.000 \\
\hline \multicolumn{6}{|l|}{ Clinical phenotype } \\
\hline Warm \& dry & $32(7.1)$ & $9(3.0)$ & $3(3.3)$ & $20(31.7)$ & 0.000 \\
\hline Warm \& wet & $388(86.4)$ & $259(87.5)$ & $86(95.5)$ & $43(6.8)$ & 0.000 \\
\hline Cold \& dry & $1(0.2)$ & $1(0.3)$ & 0 & 0 & 0.773 \\
\hline Cold \& wet & $28(7.4)$ & $27(9.1)$ & $1(1.1)$ & 0 & 0.002 \\
\hline \multicolumn{6}{|l|}{ Interventions } \\
\hline $\mathrm{PCl}$ & $9(2.0)$ & $8(2.7)$ & 0 & $1(1.5)$ & 0.270 \\
\hline CABG & $8(1.7)$ & $5(1.6)$ & $2(2.22)$ & $1(1.5)$ & 0.938 \\
\hline IABP & $2(0.4)$ & $2(0.6)$ & 0 & 0 & 0.597 \\
\hline ICD & $1(0.2)$ & $1(0.3)$ & 0 & 0 & 0.773 \\
\hline CRT & $2(0.4)$ & $2(0.6)$ & 0 & 0 & 0.597 \\
\hline PPI & $5(1.1)$ & $2(0.6)$ & $2(2.22)$ & $1(1.5)$ & 0.000 \\
\hline
\end{tabular}

$C K D$ chronic kidney disease, $C O P D$ chronic obstructive pulmonary disease, $C A D$ coronary artery disease, $P C I$ percutaneous coronary intervention, $C A B G$ coronary artery bypass graft, $C R T$ cardiaresynchronization therapy, ICDimplantable cardioverter defibrillator, $H F$ heart failure, $S B P$ systolic blood pressure, $D B P$ diastolic blood pressure, JVP jugular venous pressure, RVSP right ventricular systolic pressure, NTproBNP N-terminal pro-brain natriuretic peptide, IHD ischemic heart disease, $P C I$ percutaneous coronary intervention, CABG coronary artery bypass graft, IABP intra-aortic balloon pump, ICD implantable cardioverter defibrillator, $C R T$ cardiac resynchronization therapy, $P P I$ permanent pace-maker implantation, eGFR estimated glomerular filtration rate

Dietetic non-compliance was found to be the major precipitating factor for hospital admission in the study cohort across all the groups (69.4\%). This was followed by drug non-compliance (31.6\%). The other contributing factors were found to be acute coronary syndrome $(24.4 \%)$ anemia $(17.3 \%)$ and arrhythmias (16.7\%) (Table 2).

The mean (SD) length of hospital stay of the study population was 8.12 days (3.28) about $68.5 \%$ of patients in HFrEF group had a hospital stay of more than 5 days, while $26.6 \%$ and $33.3 \%$ of patients in HFmrEF and HFpEF group had above 5 days of hospital stay.
The NYHA functional class of heart failure patients assessed at the time of discharge. It was found that $6.6 \%$ with HFmrEF group had NYHA class IV symptoms at discharge, followed by $4 \%$ of patients with HFrEF. Worsening renal function in hospital was noted the most in HFrEF group (39.8\%) followed by $36.6 \%$ in HFmrEF and $26.9 \%$ in HFpEF groups $(p<0.05)$. The in-hospital mortality in HFmrEF (3.3\%) was twice that of HFrEF and HFpEF groups, but this difference was not statistically significant $(p>0.05)$ (Table 3).

The in-hospital outcome of the patients were analysed with respect to their clinical phenotype. It was noted that 


\section{Usage of Neurohormonal blockers}

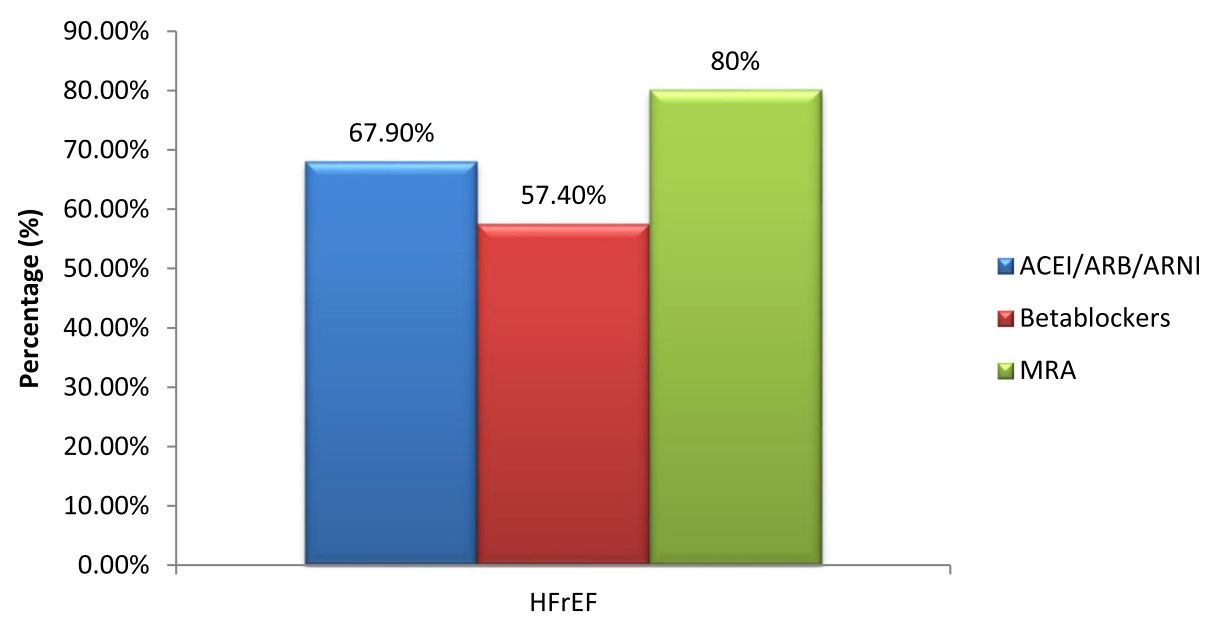

Fig. 1 Usage of neurohormonal blockers. ACEI angiotensin-converting enzyme inhibitor, ARB angiotensin receptor blocker, ARNI angiotensin receptor neprilisin inhibitor, MRA minerelocorticoid reeceptor antagonist

patients in cold and wet group (25\%) recorded the highest mortality rates followed by warm and wet group $(0.5 \%)$. The length of hospital stay of more than 5 days was highest in warm and wet category (60.3\%). NYHA class IV at the time of discharge were maximum in the cold and wet group (14.2\%). Worsening of renal function during the course in hospital was highest in cold and wet phenotype (53.5\%) (Table 4).

Univariate Cox analysis showed that patients with HFmrEF when compared to HFpEF and HFrEF was associated with increased mortality, but statistically not significant [ $p>0.005$ ] (Fig. 2). Length of in-hospital stay was increased in HFrEF, compared to HFmrEF and HFpEF [ $p=0.000]$. In comparison with clinical phenotypes, cold and wet category had increased in-hospital mortality and worsening renal function compared to other categories $[p=0.000$ and $p=$
0.001, respectively], but the length of in-hospital stay was increased in with warm and wet phenotype $[p=0.000]$.

\section{Discussion}

Our registry is a prospective observational analysis of heart failure patients from a single center in south India over a period of 1 year. Most available HF registries have classified patients based on the etiology or with respect to clinical presentation. Formerly, HF patients were classified based on LVEF as HFrEF and HFpEF. The 2016 ESC guidelines included HFmrEF as a distinct group to promote research in this gray area due to paucity of data [12]. The novelty of this registry lies in the projection of demographics, clinical characteristics, pharmacological management, and in-hospital outcome characteristics in

Table 2 Precipitating factors for heart failure

\begin{tabular}{|c|c|c|c|c|c|}
\hline & $\begin{array}{l}\text { Total } \\
n=449\end{array}$ & $\begin{array}{l}\text { HFrEF } \\
n=296 \text { (65.9\%) }\end{array}$ & $\begin{array}{l}\text { HFmrEF } \\
n=90(20 \%)\end{array}$ & $\begin{array}{l}\text { HFpEF } \\
n=63(14.03 \%)\end{array}$ & $p$ value \\
\hline Drug non-compliance & $190(42.3)$ & $142(31.6)$ & $28(31.1)$ & $20(31.7)$ & 0.001 \\
\hline Increased fluid/salt intake & $418(93)$ & $312(69.4)$ & 80(88.8) & $26(36.5)$ & 0.089 \\
\hline Acute Infections & $55(12.2)$ & $41(9.1)$ & 12(13.3) & $2(3.1)$ & 0.092 \\
\hline Arrhythmias & $75(16.7)$ & $56(12.4)$ & 15(16.6) & $4(6.3)$ & 0.000 \\
\hline ACS & $110(24.4)$ & $82(18.2)$ & $16(17.7)$ & $12(19.0)$ & 0.000 \\
\hline Acute valvular pathology & $55(12.3)$ & $41(9.1)$ & $8(8.8)$ & $6(9.5)$ & 0.000 \\
\hline Thyrotoxicosis & $16(3.5)$ & $12(2.6)$ & $2(2.2)$ & $2(3.1)$ & 0.122 \\
\hline Accelerated hypertension & $19(4.2)$ & $14(3.1)$ & $2(2.2)$ & $3(4.7)$ & 0.017 \\
\hline Pulmonary thromboembolism & $3(0.6)$ & $2(0.4)$ & $1(1.1)$ & 0 & 0.773 \\
\hline Anemia & $78(17.3)$ & $58(12.9)$ & $15(16.6)$ & $5(7.9)$ & 0.043 \\
\hline
\end{tabular}

ACS acute coronary syndrome 
Table $\mathbf{3}$ In-hospital outcome: based on ejection fraction (univariate analysis)

\begin{tabular}{|c|c|c|c|c|c|}
\hline & $\begin{array}{l}\text { Total } \\
n=449 \text { (\%) }\end{array}$ & $\begin{array}{l}\text { HFrEF } \\
n=296(65.9 \%)\end{array}$ & $\begin{array}{l}\text { HFmrEF } \\
n=90(20 \%)\end{array}$ & $\begin{array}{l}\text { HFpEF } \\
n=63(14.03 \%)\end{array}$ & $p$ value \\
\hline In-hospital mortality (cardiac) & $9(2)$ & $5(1.6)$ & $3(3.3)$ & $1(1.5)$ & 0.137 \\
\hline Length of in-hospital stay (days) [ $>5$ days] & $248(55.2)$ & 203(68.5) & $24(26.6)$ & $21(33.3)$ & 0.000 \\
\hline NYHA IV at discharge & $18(4)$ & $12(4)$ & $6(6.6)$ & 0 & 0.890 \\
\hline WRF at discharge [ $>30 \%$ from baseline] & $168(37.4)$ & $118(39.8)$ & $33(36.6)$ & $17(26.9)$ & 0.042 \\
\hline
\end{tabular}

NYHA New York Heart Association, WRF worsening renal function

LVEF-based subgroups as well as clinical phenotypebased subgroups.

As single-centered registries are limited and inconsistent, we compared our findings with multicenter registries. In comparison to other international cohorts, our

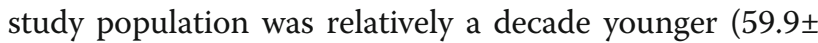
13.3) $[10,13-16]$ and was comparable to THFR, a south Indian registry $(61.2 \pm 13.7)$ and Indian subcontinent AHF patients in the Gulf acute heart failure registry $(54 \pm 11)[4,6]$. The younger cohort in the Indian subset could possibly be due to higher prevalence of ischemic heart disease at a younger age in this geographical region, which might predispose for the development of $\mathrm{HF}$ [17].

HFrEF and HFmrEF made a substantial portion of the study population. The higher prevalence of HFrEF and HFmEF could be explained by the setting of our study, being hospital inpatients as opposed to HF registries [18] which included patients from outpatient clinics.

The study population predominantly comprised of male patients. This finding was in contrast to the USAbased ADHERE registry whereas it was in line with THFR and AFAR registries conducted in India $[6,7,15]$. This outlines increased risk factors for ischemic heart disease in males, leading to HF [19]. Male preponderance were higher in HFrEF and HFmrEF whereas the female dominance was higher in HFpEF group, which is in accordance with previous data [20].

A striking difference in the clinical presentation of patients was observed. Most of the patients in this registry presented with acute de novo HF. This finding was similar to the Indian cohort in an ethnic-based comparative study in HF patients conducted in the Middle East [4]. Our finding contradicts THFR in which only $39.8 \%$ of
HF hospitalization was recorded to be acute de novo heart failure [6].

The burden of diabetes mellitus is high in South India and is a major risk factor for developing HF due to diffuse multivessel disease, recurrent MI, etc. [11]. Type II diabetes mellitus was thus unsurprisingly the most common comorbidity in patients with HFrEF and HFmrEF. As foreseen, hypertension was the most common comorbidity in HFpEF patients, which was in consensus to the study conducted by LyuSiqi, which evaluated the clinical characteristics and prognosis of HF based on LVEF [21].

CAD was the most common comorbidity across the entire spectrum of HF patients. CAD alone was noted in $52.5 \%$ of the patients, which was comparable to several international multicenter registries in which overall prevalence ranged from $40-61 \%[14,15,20]$. It highlights the global IHD burden which could lead to cardiac remodeling and further progression to heart failure [22].

Echocardiographic findings in our registry showed a higher incidence of LVH and RV dysfunction in HFpEF group compared to other patients. These findings confirmed the fact that left ventricular hypertrophy due to systemic hypertension is an important cause for diastolic dysfunction and HFpEF [23].

The prevalence of anemia in the study cohort was $41.6 \%$, which was more than comparable cohorts. The Swedish HF registry [24] reported a prevalence of anemia in $34 \%$ of the population and the HF registry of the "Get with the guideline" population [25] reported anemia in only $14 \%$ of the population. In this registry, anemia was more common in HFmrEF group. This contradicts the findings of previous research which estimated higher prevalence of anemia in higher EF $[24,25]$.

Table 4 In-hospital outcome: based on clinical phenotypes (univariate analysis)

\begin{tabular}{|c|c|c|c|c|c|c|}
\hline & $\begin{array}{l}\text { Total } \\
n=449 \text { (\%) }\end{array}$ & $\begin{array}{l}\text { Warm \& dry } \\
n=32(7.1 \%)\end{array}$ & $\begin{array}{l}\text { Warm \& wet } \\
n=388(86.4 \%)\end{array}$ & $\begin{array}{l}\text { Cold \& dry } \\
n=1(0.2 \%)\end{array}$ & $\begin{array}{l}\text { Cold \& wet } \\
n=28(6.2 \%)\end{array}$ & $p$ value \\
\hline In-hospital mortality (cardiac) & $9(2)$ & 0 & $2(0.5)$ & 0 & $7(25)$ & 0.000 \\
\hline Length of in-hospital stay (days) [ $>5$ days] & $248(55.2)$ & $4(12.5)$ & $234(60.3)$ & 0 & $10(35.7)$ & 0.000 \\
\hline NYHA IV at discharge & $18(4)$ & 0 & $14(3.6)$ & 0 & $4(14.2)$ & 0.087 \\
\hline WRF at discharge [ $>30 \%$ from baseline] & $170(37.8)$ & $8(25)$ & $147(37.8)$ & 0 & $15(53.5)$ & 0.001 \\
\hline
\end{tabular}

NYHA New York Heart Association, WRF worsening renal function 


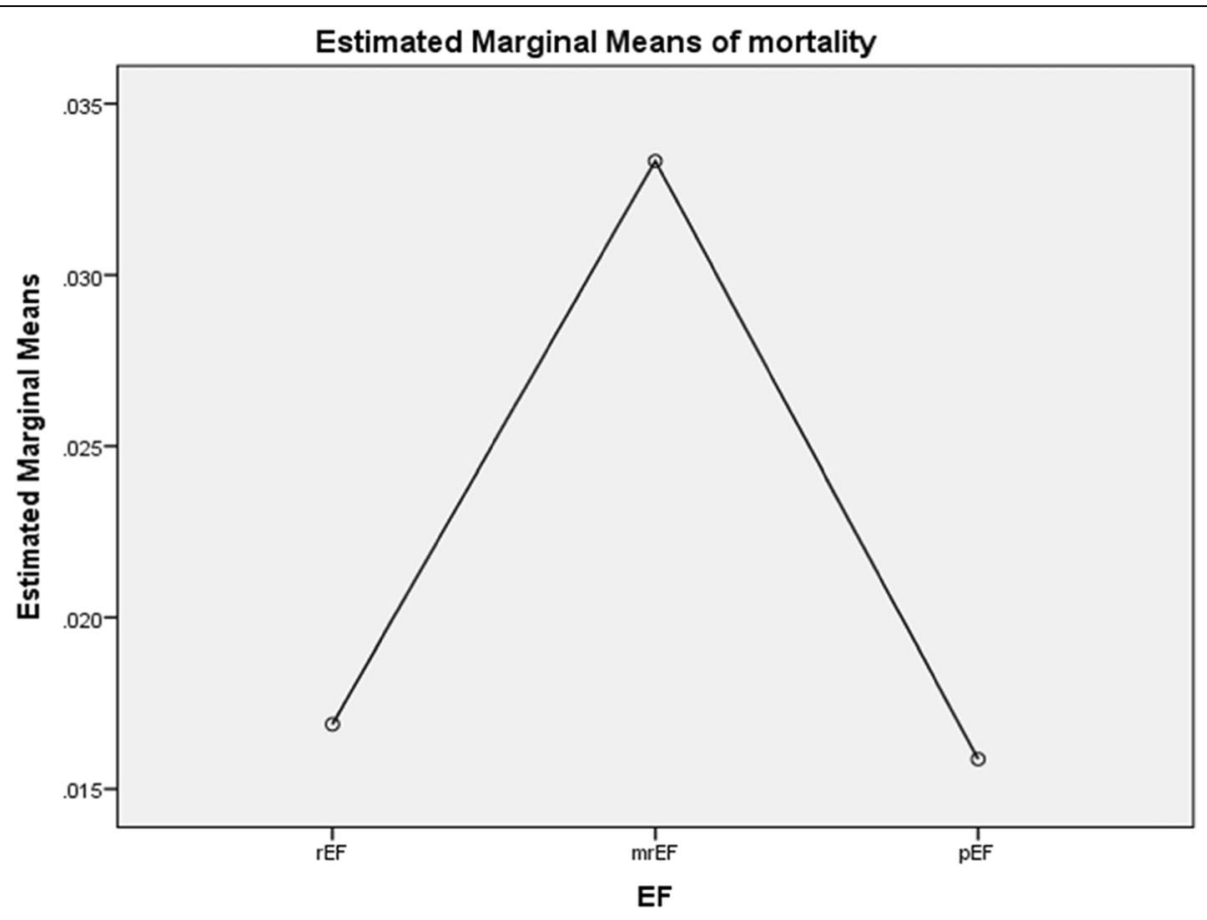

Fig. 2 Univariate analysis for mortality in patients admitted with heart failure. rEF reduced ejection fraction, mrEF mid-range ejection fraction, pEF preserved ejection fraction

Importantly, iron deficiency was the most common cause of anemia in the study cohort (93.6\%). Among the $24.9 \%$ of patients without anemia, iron deficiency was prevalent in $30.63 \%$, which was comparable to another hospital-based observational study of the anemia profile in HF patients in India [26].

Although, not significant, hyponatremia and hypokalemia were observed in the study population were higher in the HFrEF group which could be attributed to the aggressive intravenous diuretic use $(p>0.05)$, whereas hyperkalemia was found to be higher in the HFpEF group $(p=0.416)$.

Dietetic and therapeutic non-compliance was the most common precipitating factor for HF hospitalization in the entire study population. This finding reflects the need of multidisciplinary chronic disease management clinics and patient counseling to reinforce medication and dietary adherence.

It was found that the usage of guideline-directed medical therapy (GDMT) in HFrEF patients in our study higher than comparable cohort in India $[6,27]$. A multidisciplinary HF team and an on-going clinical audit of discharge prescriptions for evidence-based medication in HF have been proven to uplift the quality of HF management, which is being adopted at our center [28].

About $13.1 \%$ of patients in the HFrEF group and $7.7 \%$ of patients in the HFmrEF group were initiated on inotropes, whereas none of the patients in the HFpEF group had undergone inotropic treatment. The usage of inotrope in hospital was similar to THFR [6].

India, being a low-middle income country, ICD and CRT rates in the study population were minimal as opposed to other HF registries. Though eligible patients were offered device therapy, because of financial reasons the number of patients who underwent device therapy was noted to be low in our registry.

The overall mortality rate of HF patients over a period of 1 year in this study was $2 \%$, opposed to higher mortality rates in several previously published data. The inhospital mortality was comparable in all the three EF based subgroups $(p>0.05)$. This result is inconsistent with previous research in which the prognosis of the HFmrEF group was intermediate to HFrEF and HFpEF $[29,30]$.

Reduced EF was associated with longer length of hospital stay $(p=0.000)$; probably due to higher fluid overload requiring aggressive intravenous diuretic use, diuretic resistance, and time required to stabilize patients on GDMT. The difference between the LVEFbased subgroups in terms of NYHA IV symptoms at the time of discharge was statistically not significant $(p>0.05)$. Worsening renal function at the time of discharge of the HF patients in our study was significantly more in HFrEF group $(p=0.042)$. This reflects diuretic or ACEI-induced acute kidney injury and higher incidence of hypoperfusion in this subgroup. 
Association of in-hospital mortality with the clinical phenotype of patients showed a higher rate of inhospital deaths in cold and wet phenotype $(p=0.000)$, confirming that hypoperfusion is a marker of HF severity is associated with poor outcomes [31,32]. Length of stay in the hospital significantly exceeded in patients with warm and wet phenotype ( $p=0.000)$, which can be attributed to the intravenous diuretic use. Worsening renal function in the hospital was also noted to be higher in cold and wet phenotype ( $p=0.001)$ probably due to associated hemodynamic changes. The NYHA IV symptoms among patients did not vary significantly between the clinical phenotype-based subgroups.

This study has limitations inherent to most observational studies. It was a single-center study and data was collected by a single observer. We failed to comprehensively compare our findings with other indian hospitalbased registries, and as to date, there is no single center or multicentre national registries in India that has elaborated on clinical characteristics and outcomes of patients based on LVEF and clinical phenotype. Details about a target dose of mandated drugs and follow-up data of patients were not extracted in this study. Cardiac rehabilitation of in-hospital patients, including 6 minute walk distance and cardiopulmonary exercise test (CPET) were not feasible in all patients; hence, the data were not included in the registry.

\section{Conclusion}

This prospective HF registry exhibits systematic characterization of patients admitted with HF. We have elaborated the causes of decompensation, clinical characteristics, management, and in-hospital outcome of HF patients based on their LVEF and clinical phenotype. There is a striking disparity in the aforementioned parameters across the EF-based subgroups when compared to other international cohorts. Our study thus highlights the pressing need of native HF guidelines in low-resource countries in order to address population-specific problems in the prevention and management of $\mathrm{HF}$.

\footnotetext{
Abbreviations

HF: Heart failure; EF: Ejection fraction; HFrEF: Heart failure with reduced ejection fraction; HFmrEF: Heart failure with midrange ejection fraction; HFpEF: Heart failure with preserved ejection fraction; GDMT: Guideline disrected medical therapy; LVEF: Left ventricular ejection fraction; $\mathrm{PCl}$ : Percutaneous coronary intervention; CABG: Coronary artery bypass grafting; IABP: Intra-aortic balloon pump; ICD: Implantable cardioverter defibrillator; CRT: Cardiacresynchronization therapy; PPI: Permanent pacemaker implantation; CAD: Coronary artery disease; CKD: Chronic kidney disease; COPD: Chronic obstructive pulmonary disease; ACEl: Angiotensinconverting enzyme inhibitor; ARB: Angiotensin receptor blocker; ARNI: Angiotensin receptor neprilysin inhibitor; MRA: Minerelocorticoid receptor antagonist; NYHA: Newyork heart assoaciation;
}

CPET: Cardiopulmonary exercise test

Acknowledgements

Not applicable

\section{Authors' contributions}

All authors contributed to the research equally. AA collected the data based on the inclusion criteria and analyzed the results. NE drafted the manuscript as per journal requirements. SR supervised and coordinated the work and revised the final edition of the manuscript. SV contributed to the statistical analysis. RG, TK, PA, RP, VB, VD, and AK revised the patient's data

echocardiographic, coronary intervention details, and patient treatment. The authors read and approved the final manuscript.

\section{Funding}

The author of this manuscript declares not receiving any fund for this project.

\section{Availability of data and materials}

The manuscript data is available on request to the corresponding author.

\section{Declarations}

The submitted article is an original article and has not been published before.

Consent for publications

Not applicable

\section{Ethics approval and consent to participate}

Patients were included after written consent was signed by the patients. The institutional human ethics committee of PSG Institute of Medical Sciences and Research gave the approval number 19/275.

\section{Competing interests}

The author declares that there are no competing interests.

\section{Author details}

${ }^{1}$ Department of Cardiology, PSG Institute of Medical Sciences and Research, Coimbatore, Tamilnadu, India. ${ }^{2}$ Department of Pharmacy Practice, PSG

College of Pharmacy, Coimbatore, Tamilnadu, India.

Received: 12 February 2021 Accepted: 15 April 2021

Published online: 01 May 2021

\section{References}

1. Taylor CJ, Ordóñez-Mena JM, Roalfe AK, Lay-Flurrie S, Jones NR, Marshall T et al (2019) Trends in survival after a diagnosis of heart failure in the United Kingdom 2000-2017: population based cohort study. BMJ 364:1223. https:// doi.org/10.1136/bmj.I223

2. Lee WC, Chavez YE, Baker T, Luce BR (2004) Economic burden of heart failure: a summary of recent literature. Heart Lung 33(6):362-371. https://doi. org/10.1016/j.hrtlng.2004.06.008

3. Dokainish H, Teo K, Zhu J, Roy A, AlHabib KF, ElSayed A et al (2017) Global mortality variations in patients with heart failure: results from the international congestive heart failure (INTER-CHF) prospective cohort study. Lancet Glob Health 5(7):e665-e672. https://doi.org/10.1016/\$2214-109X(17)3 0196-1

4. Panduranga P, Al-Zakwani I, SulaimanK A-HK, Alsheikh-Ali A, Al-Suwaidi J et al (2016) Comparison of Indian subcontinent and Middle East acute heart failure patients: results from the Gulf acute heart failure registry. Indian Heart J 68:36-44

5. Chaturvedi V, Parakh N, Seth S, Bhargava B, Ramakrishnan S, Roy A et al (2016) Heart failure in India: the INDUS (INDiaUkieri study) study. J PractCardiovasc Sci. 2:28-35

6. Harikrishnan S, Sanjay G, Anees T, Viswanathan S, Vijayaraghavan G, Bahuleyan CG, Sreedharan M, Biju R, Nair T, Suresh K, Rao AC, Dalus D, Huffman MD, Jeemon P, for the Trivandrum Heart Failure Registry (2015) Clinical presentation, management, in-hospital and 90-day outcomes of heart failure patients in Trivandrum, Kerala, India: the Trivandrum heart failure registry. Eur J Heart Fail 17(8):794-800. https://doi.org/10.1002/ejhf.283

7. Seth S, Khanal S, Ramakrishnan S, Gupta N, Bahl V (2015) Epidemology of acute decompensated heart failure in India: the Afar study (acute failure registry study). J PractCardiovasc Sci 1:35-38

8. Onteddu SH, Wangchuk G, Sharma AJ, Mohan JC (2020) Acute decompensated heart failure in a north Indian community hospital: 
demographics, clinical characteristics, comorbidities and adherence to therapy. Indian Heart J 72(1):27-31. https://doi.org/10.1016/j.ihj.2020.03.004

9. John KJ, Turaka VP, Mururga Bharathy K, Vignesh Kumar C, Jayaseelan L, Visalakshi J et al (2020) Predictors of mortality, strategies to reduce readmission, and economic impact of acute decompensated heart failure: results of the Vellore heart failure registry. Indian Heart J 72(1):20-26. https://doi.org/10.1016/j.ihj.2020.03.005

10. O'Connor CM, Abraham WT, Albert NM, Clare R, Gattis Stough W, Gheorghiade $\mathrm{M}$ et al (2008) Predictors of mortality after discharge in patients hospitalized with heart failure: an analysis from the organized program to initiate lifesaving treatment in hospitalized patients with heart failure (OPTIMIZE-HF). Am Heart J 156(4):622-673

11. Kaveeshwar SA, Cornwall J (2014) The current state of diabetes mellitus in India. AMJ. 7(1):45-48. https://doi.org/10.4066/AMJ.2014.1979

12. Ponikowski P, Voors AA, Anker SD, Bueno H, Cleland JGF, Coats AJS, Falk V, González-Juanatey JR, Harjola VP, Jankowska EA, Jessup M, Linde C, Nihoyannopoulos P, Parissis JT, Pieske B, Riley JP, Rosano GM, Ruilope LM, Ruschitzka F, Rutten FH, van der Meer P, Authors/Task Force Members (2016) Document reviewers. 2016 ESC guidelines for the diagnosis and treatment of acute and chronic heart failure: the task force for the diagnosis and treatment of acute and chronic heart failure of the European Society of Cardiology (ESC). Developed with the special contribution of the heart failure association (HFA) of the ESC. Eur J Heart Fail 18(8):891-975. https:// doi.org/10.1002/ejhf.592

13. Greene SJ, Fonarrow GC, Solomon SD, Subacius H, Maggioni AP, Böhm M et al (2015) Global variation in clinical profile, management, and postdischarge outcomes among patients hospitalizes for worsening chronic heart failure: findings from the ASTRONAUT trial. Eur J art Fail 17(6):591-600. https://doi.org/10.1002/ejhf.280

14. Young YJ, Yoo BS, Lee JW, Kim JY, Han SW, Jeon ES et al (2012) Treatment performance measures affect clinical outcomes in patients with acute systolic heart failure: report from the Korean heart failure registry. Circ J 76(5):1151-1158. https://doi.org/10.1253/circj.CJ-11-1093

15. Atherton JJ, Hayward CS, Wan Ahmad WA, Kwok B, Jorge J, Hernandez AF, Liang L, Kociol RD, Krum H, ADHERE International-Asia Pacific Scientific Advisory Committee (2012) Patient characteristics from a regional multicenter database of acute decompensated heart failure in Asia Pacific (ADHERE international-Asia Pacific). J Card Fail 18(1):82-88. https://doi.org/1 0.1016/j.cardfail.2011.09.003

16. Spinar J, Parencia J, Vitovec J, Widimsky P, Linhart A, Fedorco M et al (2011) Baseline characteristics and hospital mortality in the acute heart failure database (AHEAD) main registry. Crit Care 15(6):R291. https://doi.org/10.11 86/cc10584

17. Sharma M, Ganguly N (2005) K. Premature coronary artery disease in Indians and its associated risk factors. Vasc Health Risk Manag 1(3):217-225

18. Schjodt I, Nakano A, Egstrup K, Cerqueira C (2016) The Danish heart failure registry. ClinEpidemol::497-502

19. Azad N, Kathirvelu A, Minoospeher S, Hebert P, Fergusson D (2011) Gender differences in the etiology of heart failure: a systemic review. J GeriatrCardiol 8(1):15-23

20. Shah KS, Xu H, Matsouka RA, Bhatt DL, Heidenreich PA, Hernandez AF et al (2017) Heart failure with preserved, borderline, and reduced ejection fraction: 5-year outcomes. J Am CollCardiol 70(20):2476-2486. https://doi. org/10.1016/j.jacc.2017.08.074

21. Lyu S, Yu L, Tan H, Liu S, Liu X, Guo X, Zhu J (2019) Clinical characteristics and prognosis of heart failure with mid-range ejection fraction: insights from a multi-centreregistry study in China. BMC Cardiovasc Disord 19(1):209. https://doi.org/10.1186/s12872-019-1177-1

22. Hsu JJ, Ziaein B, Fonarow GC (2017) Heart failure with mid-range (borderline) ejection fraction: clinical implications and future directions. JACC Heart Fail 5(11):763-771. https://doi.org/10.1016/j.jchf.2017.06.013

23. Heush G, Libby P, Gersh B, Yellon D, Böhm M, Lopaschuk G et al (2014) Cardiovascular remodeling in coronary artery disease and heart failure. Lancet. 383(9932):1933-1943. https://doi.org/10.1016/S0140-6736(14)60107-0

24. Tam MC, Lee R, Cascino TM (2017) Current perspectives on systemic hypertension in heart falure with preserved ejection fraction. CurrHypertens Rep 19(2):12. https://doi.org/10.1007/s11906-017-0709-2

25. Savarese G, Jonsson $\AA$, Hallberg AC, Dahlström U, Edner M, Lund LH (2020) Prevelence of, associations with, and prognostic role of anemia on heart failure across the ejection fraction spectrum. Int J Cardiol 298:59-65. https:// doi.org/10.1016/j.jijcard.2019.08.049
26. Mentz RJ, Kelly JP, von Leuder TG, Voors AA, Lam CS, Cowie MR et al (2014) Noncardiac comorbidities in heart failure with reduced versus preserved ejection fraction. J Am CollCardiol. 64(21):2281-2293. https://doi.org/10.101 6/j.jacc.2014.08.036

27. Arora H, Sawhney JPS, Mehta A, Mohanty A (2018) Anemia profile in patients with congestive heart failure a hospital based observational study. Indian Heart J 70(3):101-104

28. Pokharel Y, Wei J, Hira RS, Kalra A, Shore S, Kerkar PG et al (2016) Guidelinedirected medication use in patients with heart failure with reduced ejection fraction in India: American College of Cardiology's PINNACLE India quality improvement program. ClinCardiol. 39(3):145-149

29. Shukkoor AA, George NE, Radhakrishnan S, Velusamy S, Kaliappan T, Gopalan R et al (2020) Impact clinical audit on adherence to the guidelines directed medical therapy in patients admitted with heart failure. Curr Drug Saf 15(2):117-123. https://doi.org/10.2174/1574886315666200310114528

30. Ibrahim NE, Song Y, Cannon CP, Doros G, Russo P, Ponirakis A, Alexanian C, Januzzi JL Jr (2019) Heart failure with mid-range ejection fraction: characterization of patients from the PINNACLE registry ${ }^{\circledast}$. ESC Heart Fail 6(4): 784-792. https://doi.org/10.1002/ehf2.12455

31. Chioncel O, Mebazaa A, Harjola VP, Coats AJ, Piepoli MF, Crespo-Leiro MG, Laroche C, Seferovic PM, Anker SD, Ferrari R, Ruschitzka F, Lopez-Fernandez S, Miani D, Filippatos G, Maggioni AP, on behalf of the ESC Heart Failure LongTerm Registry Investigators (2017) Clinical phenotypes and outcome of patients hospitalized for acute heart failure: the ESC heart failure long-term registry. Eur J Heart Fail 19(10):1242-1254. https://doi.org/10.1002/ejhf.890

32. Harjola VP, Mullens W, Banaszewski M, Bauersachs J, Brunner-La Rocca HP, Chioncel $O$ et al (2017) Organ dysfunction, injury and failure in acute heart failure: from pathophysiology to diagnosis and management. A review on behalf of the acute heart failure Committee of the Heart Failure Association (HFA) of the European Society of Cardiology (ESC). Eur J Heart Fail 19(7): 821-836. https://doi.org/10.1002/ejhf.872

\section{Publisher's Note}

Springer Nature remains neutral with regard to jurisdictional claims in published maps and institutional affiliations.

\section{Submit your manuscript to a SpringerOpen ${ }^{\circ}$ journal and benefit from:}

- Convenient online submission

- Rigorous peer review

- Open access: articles freely available online

High visibility within the field

- Retaining the copyright to your article

Submit your next manuscript at $\boldsymbol{\nabla}$ springeropen.com 